\title{
Anthropometric Parameters, Lower Limb Functionality and Quality of Life After High-Intensity Interval Training in Healthy Young People Versus Older Adults
}

\author{
Parámetros Antropométricos, Funcionalidad de Miembros Inferiores y Calidad de Vida Posterior \\ al Entrenamiento Interválico de Alta Intensidad en Jóvenes Versus Personas Mayores
}

\begin{abstract}
Macarena Artigas-Arias ${ }^{1,2}$; María Angélica Olea ${ }^{3}$; Yuri SanMartín-Calísto ${ }^{1}$; Nolberto Huard ${ }^{4}$; Fernanda Durán-Vejar5; Francisca Beltrán-Fuentes ${ }^{5}$; Aris Muñoz-Fernández; ${ }^{5}$ Andrea Alegría-Molina ${ }^{1,5}$; Jorge Sapunar6; Luis A. Salazar ${ }^{4}$ \& Gabriel
\end{abstract} Nasri Marzuca-Nassr ${ }^{1,6}$

ARTIGAS-ARIAS, M.; OLEA, M.A.; SAN MARTÍN-CALÍSTO, Y.; HUARD, N.; DURÁN-VEJAR, F.; BELTRÁN-FUENTES, F.; MUÑOZ-FERNÁNDEZ, A.; ALEGRÍA-MOLINA, A.; SAPUNAR, J.; SALAZAR, L. A. \& MARZUCA-NASSR, G. N. Anthropometric parameters, lower limb functionality and quality of life after high-intensity interval training in healthy young people versus older adults. Int. J. Morphol., 39(5):1337-1344, 2021.

SUMMARY: The aim of this study was to determine the effects of High-intensity interval training (HIIT) on the quality of life in healthy young people (YNG) and older adults (OLD)and its correlation with physical health status (anthropometric parameters and lower limb functionality) YNG $(21 \pm 2$ years, BMI $26.37 \pm 2.69 \mathrm{n}=12)$ and OLD $(67 \pm 5$ years, BMI $27.16 \pm 3.04 \mathrm{n}=12)$ groups underwent 12 weeks of HIIT. Before and after the HIIT, anthropometric assessments, lower limb functionality tests, and SF-36 quality-of-life questionnaire were performed. There were no significant changes in the SF-36 dimensions ( $>>0.05)$. After HIIT, there were improvement percentage changes in Mental Component Summary (MCS) (YNG, $+8.51 \pm 25.80 \%$ vs. OLD, $+2.30 \pm 9.05 \%$ ) and in Physical Component Summary (PCS) (YNG, $+2.66 \pm 20.54 \%$ vs. OLD, $+4.34 \pm 22.71 \%)$. Negative correlations were observed between body mass index (BMI) with PCS $(\mathrm{R}=-0.570, \mathrm{P}=0.009)$ and with $\mathrm{MCS}(\mathrm{R}=-0.649, \mathrm{P}=0.002)$ in $\mathrm{OLD}$ as well as between MCS and waist circumference $(\mathrm{R}=-0.557, \mathrm{P} \leq 0.001)$ in both groups. Also, correlations were observed between PCS and the sit-to-stand test $(\mathrm{R}=-0.424, \mathrm{P}=0.006)$ in both groups and gait speed $(\mathrm{R}=0.458, \mathrm{P}=0.042)$ only in YNG. HIIT promotes positive percentage changes in quality of life, with YNG showing better results in PCS and OLD in MCS. Quality of life and physical health status were correlated in both groups.

KEY WORDS: High intensity interval training; Healthy aging; Anthropometry, functional ability; Quality of life.

\section{INTRODUCTION}

Aging process is complex (Rowe \& Kahn, 1987), and age-related physiological changes are not only responsible for triggering reductions in functionality, independence and quality of life in the older population (Boutros et al., 2019). The impact of healthy behaviors and lifestyles on aging and health status in the general population has been underestimated. An optimal emotional and nutritional state, and adequate levels of physical activity will provide physical, mental and social well-being, contributing important physiological reserves for the course of a person's life (Rowe \& Kahn; Boutros et al.).
Being sedentary as part of those lifestyles has been related to cardio-metabolic, physical and mental disorders, such as stress, depression and anxiety, that deeply affect selfreported well-being and quality of life, mainly in the young university population (Chang et al., 2016). In the same way, sarcopenia and being sedentary have been linked to the main risk factors associated with the development of noncommunicable chronic diseases and reduced musculoskeletal physical function after 60 years (Bouchard et al., 2011). Physical disabilities and comorbidities affect the level of per-

\footnotetext{
${ }^{1}$ Magíster en Terapia Física con menciones, Facultad de Medicina, Universidad de La Frontera, Temuco, Chile.

${ }^{2}$ Departamento de Procesos Terapéuticos, Facultad de Ciencias de la Salud, Universidad Católica de Temuco, Temuco, Chile.

${ }^{3}$ Departamento de Educación Física, Deporte y Recreación, Facultad de Educación, Ciencias Sociales y Humanidades; Universidad de La Frontera, Temuco, Chile.

${ }^{4}$ Centro de Biología Molecular y Farmacogenética, Departamento de Ciencias Básicas, Facultad de Medicina, Universidad de La Frontera, Temuco, Chile.

${ }^{5}$ Carrera de Kinesiología, Facultad de Medicina, Universidad de La Frontera, Chile.

${ }^{6}$ Departamento de Medicina Interna, Facultad de Medicina, Universidad de La Frontera, Temuco, Chile.
} 
ARTIGAS-ARIAS, M.; OLEA, M. A.; SAN MARTÍN-CALÍSTO, Y.; HUARD, N.; DURÁN-VEJAR, F.; BELTRÁN-FUENTES, F.; MUÑOZ-FERNÁNDEZ, A.; ALEGRÍA-MOLINA, A.; SAPUNAR, J.; SALAZAR, L. A. \& MARZUCA-NASSR, G. N. Anthropometric parameters, lower limb functionality and quality of life after high-intensity interval training in healthy young people versus older adults. Int. J. Morphol., 39(5):1337-1344, 2021.

sonal satisfaction and quality of life in older adults, key components of healthy aging (Awick et al., 2017).

With changes in physical and mental health, aerobic exercise and resistance-exercise training have been demonstrated to partially counteract the cardio-metabolic and functional changes (Nelson et al., 2007; Dalmazzo et al., 2019). However, the beneficial effect of exercise on quality of life is related to the intensity of the training, both in young people and older adults (Snedden et al., 2019).

Therefore, high-intensity interval training (HIIT), characterized by brief periods of exercise of vigorous intensity interspersed with inactive recovery phases or low intensity of varying duration (MacInnis \& Gibala, 2017), has been proposed as an efficient therapeutic alternative, with intracellular effects that improve body composition, cardiorespiratory capacity, insulin sensitivity and cardiovascular risk (Liu et al., 2019). However, current research on HIIT in the healthy older adult population is limited, and proposes this type of training as a complete intervention in the improvement of physical and functional conditioning (García-Pinillos et al., 2019). Yet little it is known about the effects of HIIT on the quality of life in the healthy young or older population. Essentially, the studies that have assessed quality of life after HIIT have focused on the pathological population: diabetes mellitus (Mangiamarchi et al., 2017),Parkinson's Disease (Cancela et al., 2020) and ischemic cardiopathy (Villelabeitia Jaureguizar et al., 2016), finding favorable metabolic and quality-of-life outcomes in the physical and mental health components (measured through the SF-36 questionnaire) (Villelabeitia Jaureguizar et al.; Mangiamarchi et al.; Adams et al., 2018). Consequently, and based on the aforementioned, the purpose of the following study was to determine if HIIT is beneficial as a multidimensional health intervention to improve quality of life in healthy men.

We hypothesize that after 12-week of HIIT, improvements will be observed in the quality of life through the SF-36 questionnaire in young people and older adults. In addition, significant correlations will be presented between quality of life and physical health assessment parameters (anthropometry and lower limb functionality).

\section{MATERIAL AND METHOD}

This study is secondary to a wider project that determined the effect of HIIT on several health parameters between young people vs. older adults, which already has a publication (Marzuca-Nassr et al., 2020).This research was approved by the Scientific Ethics Committee of the Universidad de La Frontera (Minutes No069_18, Page 025_18).

Subjects. Twenty four subjects all, twelve young people (YNG; age, $21 \pm 2 \mathrm{y}$; weight, $77.16 \pm 9.96 \mathrm{~kg}$; body mass index [BMI], $26.37 \pm 2.69 \mathrm{~kg} \cdot \mathrm{m}-2)$ and twelve older adults (OLD; age, $67 \pm 5 \mathrm{y}$; weight, $76.86 \pm 11.33 \mathrm{~kg}$; body mass index $[\mathrm{BMI}], 27.16 \pm 3.04 \mathrm{~kg} \cdot \mathrm{m}-2)$ were recruited to participate in the current study, who complied with the inclusion criteria (males between 18-35 and 55-75 years of age; sedentary; BMI above 18.5 or below $30 \mathrm{~kg} \cdot \mathrm{m}-2$ ), and the exclusion criteria (surgery within 3 months prior to the screening; use of anticoagulants; musculoskeletal or orthopedic injuries; type 2 diabetes mellitus (determined by fasting blood glucose $>100$ $\mathrm{mg} / \mathrm{dl}$ or HbA1c-values $>6.5 \%$ ); uncontrolled high blood pressure; use of nutritional supplementation that can regulate skeletal muscle mass or cardiorespiratory capacity; smoker; thrombosis event in the family; and/or severe cardiac problems) and who also provided an informed consent in writing.

Subjects completed a routine medical screening and general health questionnaire to ensure their suitability to take part in the study, one week before the study. Later, separate tests were performed (test $1, \mathrm{PRE}$ and test $2, \mathrm{POST}$ ) on two occasions.

Forty-eight hours before the first session and 48 hours after the last training session, a series of measurements was taken, which included an anthropometric parameter, lower limb functionality assessment and self-reported quality-of-life questionnaire (SF-36).

Anthropometric Parameters. Weight was measured on a SECA ${ }^{\circledR}$ platform scale (Madison, WI, USA) with a graduation of $0.1 \mathrm{~kg}$ and height was measured to an accuracy of $0.5 \mathrm{~cm}$ using a stadiometer coupled to the scale, with the subject barefoot. Body mass index (BMI) was also calculated using the formula proposed by Rolland-Cachera et al. (1991) (weight in $(\mathrm{kg}) /$ height 2 in $(\mathrm{m}))$. Waist circumference was measured with a SECA ${ }^{\circledR}$ tape measure graduated in centimeters (Madison, WI, USA). The evaluation was performed in exhalation at the midpoint between the lower rib and iliac crest of the right half of the body.

Lower limb functionality. Sit-to-stand test and gait speed were included as key assessments in lowerlimb functionality, assessed by the Short Physical Performance Battery (SPPB) (Guralnik et al., 1994).

The sit-to-stand test was performed in an armless chair. Subjects were asked to sit with their arms crossed in front of their chest during execution of the test. The best time of 5 repetitions was recorded. 
ARTIGAS-ARIAS, M.; OLEA, M. A.; SAN MARTÍN-CALÍSTO, Y.; HUARD, N.; DURÁN-VEJAR, F.; BELTRÁN-FUENTES, F.; MUÑOZ-FERNÁNDEZ, A.; ALEGRÍA-MOLINA, A.; SAPUNAR, J.; SALAZAR, L. A. \& MARZUCA-NASSR, G. N. Anthropometric parameters, lower limb functionality and quality of life after high-intensity interval training in healthy young people versus older adults. Int. J. Morphol., 39(5):1337-1344, 2021.

Gait speed was evaluated in a long, unobstructed hallway with a non-slip surface. Subjects walked a distance of 4 meters at their usual speed on two occasions, recording the shortest time. With this result, each participant's gait speed was determined in meters $(\mathrm{m}) /$ seconds $(\mathrm{s})$.

Quality of life questionnaire: The Short Form-36 Health Survey (SF-36). SF-36 quality-of-life questionnaire was used (Ware \& Sherbourne, 1992). The present self-reported generic scale provides a profile of the overall state of health, validated for users with concomitant pathologies or the general population, with an estimation of reliability using a Cronbach's alpha greater than 0.70 in both dimensions (physical and psychological) (Ware \& Sherbourne). The questionnaire consists of 36 items; 8 dimensions: physical function (10); physical role (4); bodily pain (2); general health (5); vitality (4); social function (2); emotional role (3); mental health (5), one item on health transition (1) and 2 component summaries of Physical Component Summary (PCS) and Mental Component Summary (MCS).

The score goes between 0 to $100 \%$, where a higher score implies a better health-related quality of life (Ware \& Sherbourne).

High-intensity interval training. HIIT was done for 12 weeks (3x/week) on a stationary bicycle (Oxford $囚$, BE2700) under personalized supervision and continuous heart rate monitoring (Polar T31 transmitter, Finland). A resistance that caused muscle fatigue after 1 minute of exercise at a speed between $30-40 \mathrm{~km} / \mathrm{h}$ was applied in each session. This was done using the heart rate observed during the $\mathrm{VO} 2$ maxtest as a reference. After this, there were $2 \mathrm{~min}$ of inactive rest, repeating each interval of exercise/rest 10 times (Marzuca-Nassr et al.).

Statistics. All the statistical analyses were performed using the SPSS software (version 25.0, Chicago, Illinois, USA). The level for statistical significance was set at $\mathrm{P}<0.05$. All the data are expressed as mean \pm standard deviation (SD) to describe the variables. The data before and after the intervention were analyzed using a repeated measures ANOVA with time (PRE vs. POST) as the intra-subject and group (YNG vs. OLD) as the inter-subject factor. In case of a significant interaction, pair wise t-tests were performed to determine the effects of time within the groups and independent t-tests for the group differences in the PRE and POST intervention values. Also, the delta percentage(D\%) between the PRE and POST intervention of each of the subjects was calculated in relation to the SF-36 dimensions and analyzed with an independent t-test. Finally, the Pearson test was used to determine the correlation between the changes in anthropometry parameters, lower limb functionality and SF-36 questionnaire central components.

\section{RESULTS}

Subjects. Basal characteristics of the subjects are shown in Table I. At the beginning of the intervention, there were significant differences between YNG and OLD only in age $(\mathrm{P}=0.009)$.

Table I. Basal characteristics of the subjects.

\begin{tabular}{lcc}
\hline & YNG $(n=12)$ & OLD $(n=12)$ \\
\hline Age $(\mathrm{y})$ & $21 \pm 2$ & $67 \pm 5^{* *}$ \\
Weight $(\mathrm{kg})$ & $77.16 \pm 9.96$ & $76.86 \pm 11.33$ \\
Height $(\mathrm{m})$ & $1.71 \pm 0.06$ & $1.67 \pm 0.06$ \\
BMI $(\mathrm{kg} \cdot \mathrm{m}-2)$ & $26.37 \pm 2.69$ & $27.16 \pm 3.04$ \\
W aist circumference & 89.75 & 97.65 \\
$(\mathrm{~cm})$ & & \\
SBP (mm Hg) & $126.67 \pm 5.61$ & $127.67 \pm 9.35$ \\
DBP $(\mathrm{mm} \mathrm{Hg})$ & $79.58 \pm 6.58$ & $79.83 \pm 7.87$ \\
HR (lpm) & $71.17 \pm 12.63$ & $68.83 \pm 10.10$ \\
\hline
\end{tabular}

YNG: young group; OLD: older group; BMI: body mass index; SBP: systolic blood pressure; DBP: diastolic blood pressure; HR: heart rate. Values represent means $\pm \mathrm{SD} ; * *$ Significantly different from YNG at the $<0.01$ level.

After 12 weeks of HIIT training, 2 young people and 2 older adults were lost, who withdrew due to personal or physical issues not related to the HIIT. In total, 20 subjects completed the study. Therefore, the following results are based on this quantity (YNG, $\mathrm{n}=10$ vs. OLD).

Anthropometric parameters. Table II provides the anthropometric results between PRE and POST of the subjects who completed the intervention program. There were no significant inter- or intra-group differences $(\mathrm{P}>0.05)$ between YNG and OLD in body weight, BMI or waist circumference.

Table II. Anthropometric measurements before and after 12-week of HIIT program.

\begin{tabular}{lcccc}
\hline & \multicolumn{2}{c}{ YNG $(n=10)$} & \multicolumn{2}{c}{ OLD $(n=10)$} \\
& Pre & \multicolumn{1}{c}{ Post } & Pre & Post \\
\hline Weight $(\mathrm{Kg})$ & $75.76 \pm 9.99$ & $75.03 \pm 9.62$ & $77.99 \pm 11.40$ & $78.06 \pm 11.82$ \\
BMI $\left(\mathrm{kg} \cdot \mathrm{m}^{-2}\right)$ & $26.01 \pm 2.64$ & $25.89 \pm 2.18$ & $27.43 \pm 3.12$ & $27.83 \pm 3.18$ \\
Waist & $89.17 \pm 9.16$ & $90.10 \pm 13.03$ & $99.12 \pm 9.82$ & $98.74 \pm 9.95$ \\
\hline
\end{tabular}

HIIT: high-intensity interval training, YNG: young group; OLD: older group; PRE: Pre-intervention; POS: Post-intervention; BMI: body mass index. Values represent means \pm SD. 
ARTIGAS-ARIAS, M.; OLEA, M. A.; SAN MARTÍN-CALÍSTO, Y.; HUARD, N.; DURÁN-VEJAR, F.; BELTRÁN-FUENTES, F.; MUÑOZ-FERNÁNDEZ, A.; ALEGRÍA-MOLINA, A.; SAPUNAR, J.; SALAZAR, L. A. \& MARZUCA-NASSR, G. N. Anthropometric parameters, lower limb functionality and quality of life after high-intensity interval training in healthy young people versus older adults. Int. J. Morphol., 39(5):1337-1344, 2021.

Lower limb functionality. With respect to lower limb functionality, OLD had a longer execution time in the sit-to-stand test than YNG (PRE, $\mathrm{P}=0.001$ and POST, $\mathrm{P}=0.05$ ) (Fig. 1A). After the 12-week of HIIT, the OLD group improved significantly (PRE vs. POST, $\mathrm{P}=0.009)$. 12-week of HIIT program was beneficial in significantly increasing gait speed in both groups (time effect, $\mathrm{P}=0.014$; YNG $\sim 11 \%$ vs. OLD $\sim 10 \%$ ), with no difference between groups $(\mathrm{P}=0.861)$ (Fig. 1B).

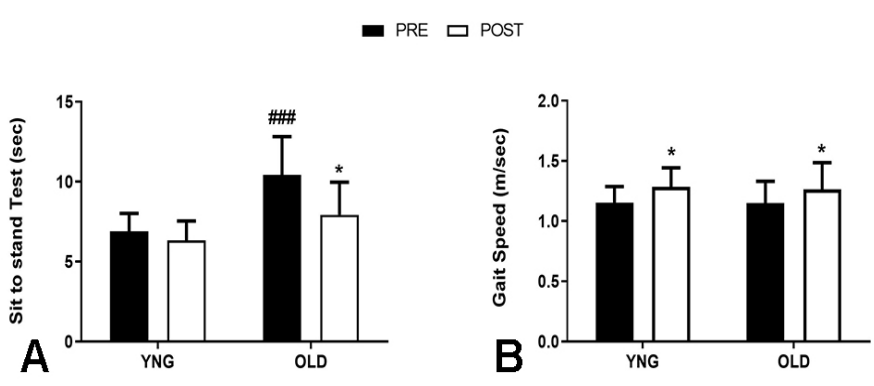

Fig. 1. Lower limb functionality before and after 12-week of HIIT program. Sit-stand changes (A), and (B) gait speed changes after 12 - week of HIIT program: high-intensity interval training, YNG: young group; OLD: older group; PRE: pre-intervention; POST: post-intervention. Sec: seconds; m/ sec: meters/seconds. * Significantly different from pre-intervention values at the $\mathrm{P}<0.05$ level; \#\#\# Significantly different inter-group at the $\mathrm{P}<0.001$ level.

Quality of life (SF-36). Physical function before and after HIIT presented differences between YNG and OLD $(\mathrm{P}=0.031)$, with the YNG subjects scoring higher (Table III).

The remaining domains did not present significant differences $(\mathrm{P}>0.05)$, despite the variations in the delta percentage of the PRE vs. POST scores obtained in each domain. However, greater percentage changes were observed in the mental component summary in YNG group (MCS $+8.51 \pm 25.80 \%$ and PCS $+2.30 \pm$ $9.05 \%)$ and in the physical component summary in OLD group $(\mathrm{PCS}+4.34 \pm 22.71 \%$ and $\mathrm{MCS}+2.66 \pm 20.54 \%)$.

Correlations between quality of life with anthropometry parameters and lower limb functionality. Pearson test was performed between quality of life and BMI.A negative correlation was noted between PCS and BMI $(\mathrm{R}=-0.570, \mathrm{P}=0.009)$ as well as between MCS and BMI $(\mathrm{R}=-0.649 \mathrm{P}=0.002)$ in OLD (Table IV). Finally, waist circumference in all the subjects was related negatively with MCS $(\mathrm{R}=-0.557, \mathrm{P}=0.000)$.

PCS also correlated moderate with the lower limb functionality, specifically in the variables gait speed in YNG $(\mathrm{R}=0.458, \mathrm{P}=0.042)$ and the sit-to-stand test in all the subjects $(\mathrm{R}=-$ $0.424, \mathrm{P}=0.006$ ) (Table V).

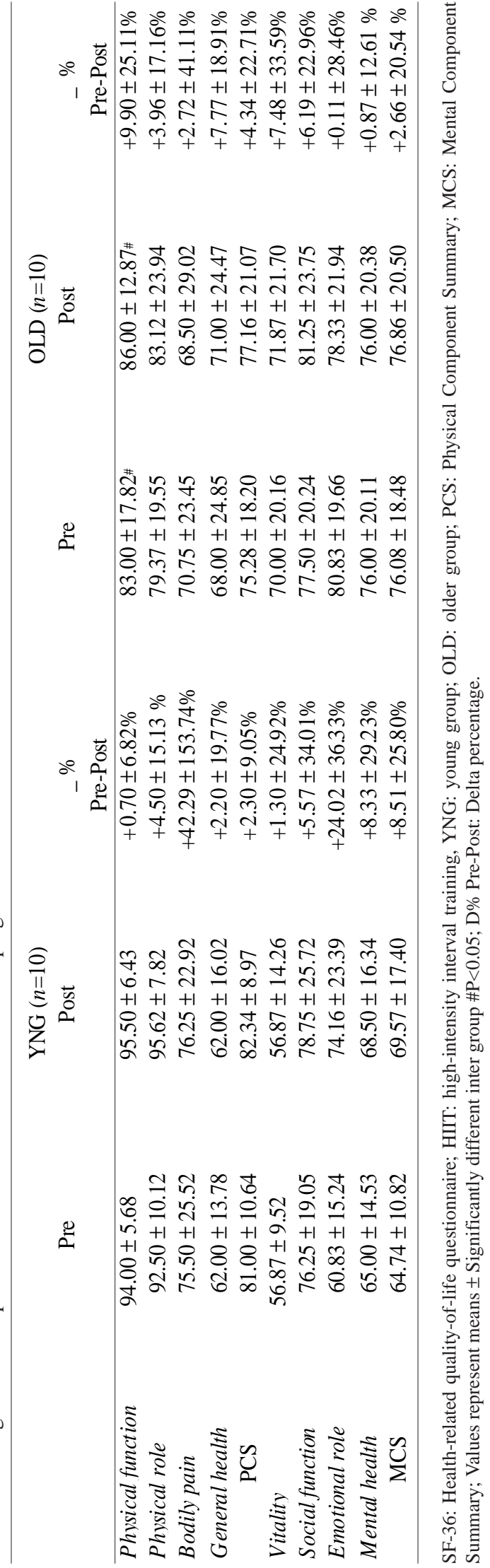


ARTIGAS-ARIAS, M.; OLEA, M. A.; SAN MARTÍN-CALÍSTO, Y.; HUARD, N.; DURÁN-VEJAR, F.; BELTRÁN-FUENTES, F.; MUÑOZ-FERNÁNDEZ, A.; ALEGRÍA-MOLINA, A.; SAPUNAR, J.; SALAZAR, L. A. \& MARZUCA-NASSR, G. N. Anthropometric parameters, lower limb functionality and quality of life after high-intensity interval training in healthy young people versus older adults. Int. J. Morphol., 39(5):1337-1344, 2021.

Table IV. Relation between SF-36 domains and anthropometric measurements before and after 12- week of HIIT program.

\begin{tabular}{|c|c|c|c|c|c|c|}
\hline \multirow{2}{*}{$\begin{array}{c}\text { Correlation } \\
\text { PCS }\end{array}$} & \multicolumn{2}{|c|}{ YNG } & \multicolumn{2}{|c|}{ OLD } & \multicolumn{2}{|c|}{ Total } \\
\hline & $\boldsymbol{R}$ & $\boldsymbol{P}$ & $\boldsymbol{R}$ & $P$ & $\boldsymbol{R}$ & $P$ \\
\hline BMI & 0.258 & 0.272 & $-0.570 * *$ & 0.009 & $-0.368 *$ & $\mathbf{0 . 0 2 0}$ \\
\hline Waist circumference & -0.078 & 0.744 & -0.364 & 0.115 & -0.296 & 0.064 \\
\hline MCS & $\boldsymbol{R}$ & $\boldsymbol{P}$ & $\boldsymbol{R}$ & $\boldsymbol{P}$ & $\boldsymbol{R}$ & $P$ \\
\hline BMI & -0.010 & 0.967 & $-0.649 * *$ & 0.002 & -0.298 & 0.061 \\
\hline Waist circumference & -0.094 & 0.693 & -0.379 & 0.100 & $-0.557 * * *$ & 0.000 \\
\hline
\end{tabular}

SF-36: Health-related quality-of-life questionnaire; HIIT: High-intensity interval training; YNG: young group; OLD: older group; PCS: Physical Component Summary; MCS: Mental Component Summary; BMI: body mass index; R: Pearson correlation. The correlation is significant at the level *: P<0.05, **: $\mathrm{P}<0.01, * * *: \mathrm{P}<0.001$ (bilateral). Bold numbers at the $\mathrm{P}<0.05$ level.

Table V: Relation between PCS and lower limb functionality before and after 12- week of HIIT program.

\begin{tabular}{lcccccc}
\hline \multicolumn{1}{c}{ Correlation } & \multicolumn{2}{c}{ YNG } & \multicolumn{2}{c}{ OLD } & \multicolumn{2}{c}{ Total } \\
\hline \multicolumn{1}{c}{ PCS } & $R$ & $P$ & $R$ & $P$ & $R$ \\
\hline Gait speed & $0.458^{*}$ & $\mathbf{0 . 0 4 2}$ & 0.256 & 0.276 & 0.307 & 0.054 \\
Sit-to-Stand test & -0.252 & 0.283 & -0.429 & 0.059 & $-0.424^{* *}$ & $\mathbf{0 . 0 0 6}$ \\
\hline
\end{tabular}

PCS: Physical Component Summary; HIIT: High-intensity interval training; YNG: young group; OLD: older group; R: Pearson correlation. The correlation is significant at the level *: $\mathrm{P}<0.05, * *: \mathrm{P}<0.01$ (bilateral). Bold numbers at the $\mathrm{P}<0.05$ level.

\section{DISCUSSION}

The aim of the study was to determine if HIIT is beneficial as a multidimensional health intervention to improve quality of life in healthy men. We hypothesized that after 12-week of HIIT program improvements would be noted in the quality of life using the SF-36 questionnaire in young people and older adults. In addition, there could significant correlations between quality of life and physical health assessment parameters. Negative correlations were observed between body mass index (BMI) with PCS and with MCS in OLD as well as between MCS and waist circumference in both groups. Also, moderate correlation was observed between PCS and the sit-to-stand test in both groups and gait speed only in YNG.

Our findings showed that after 12 weeks of HIIT on a bicycle, gait speed increased in both groups and the execution time of the sit-to-stand test decreased. There were no significant changes on the SF-36 questionnaire after the intervention, but positive percentage changes were generated in PCS in young people and MCS in older adults. Finally, there were significant correlations between the SF-36 component summaries (PCS and MCS) and anthropometric parameters in older adults, as well as between PCS and gait speed in young people and sit-to-stand in all the subjects.

Based on these results, HIIT not only promotes positive responses in physical health, but also improvements in quality of life (Kell \& Rula, 2019). With the above, it is reinforced that the practice of exercise generates benefits on the quality of life.
In this line, Snedden et al. demonstrated an inverse relationship between vigorous intensity exercise and selfreported mental health among college students.

An inadequate nutritional status (altered BMI values) in the general population independently decreases the quality of life, as a consequence of increased morbidity and deterioration of functional status (Gariballa \& Alessa, 2018).

However, these associations are little explored in the older population and the studies that have shown a direct association between BMI and quality of life in older people living in urban and rural communities are mainly from Central and Eastern European societies (Gariballa \& Alessa). However, these results coincide with the correlations observed in the present investigation (Wang et al., 2018).

In relation to physical capacity and its association with physical and mental well-being in the older population, it has been linked mainly in subjects with chronic conditions such as heart failure (Ostman et al., 2017) and hospitalized older subjects, where lower muscle strength and functionality is associated with a poor quality of health related life (Haider et al., 2016). On the contrary, this relationship is less detectable in the healthy young or older population (Dodds et al., 2014).

However, none of the young or older subjects who took part in this study presented important health comorbidities or sarcopenia according to the updated 
ARTIGAS-ARIAS, M.; OLEA, M. A.; SAN MARTÍN-CALÍSTO, Y.; HUARD, N.; DURÁN-VEJAR, F.; BELTRÁN-FUENTES, F.; MUÑOZ-FERNÁNDEZ, A.; ALEGRÍA-MOLINA, A.; SAPUNAR, J.; SALAZAR, L. A. \& MARZUCA-NASSR, G. N. Anthropometric parameters, lower limb functionality and quality of life after high-intensity interval training in healthy young people versus older adults. Int. J. Morphol., 39(5):1337-1344, 2021.

recommendations of the European Working Group on Sarcopenia in Older People (EWGSOP2) (Cruz-Jentoft et al., 2019), i.e., poor muscle strength, alteration in lower limb functionality or gait speed. Nevertheless, after the intervention of 12-week HIIT on a bicycle, there were significant improvements in lower limb functionality (sitto-stand in OLD group and gait speed in both groups) and significant correlations between quality of life and physical health status in both groups.

Our results are similar to those published by JiménezGarcía et al. (2019), who compared the effects of 12 weeks with HIIT (via Total-Body Resistance Exercise - TRX suspension training) vs. moderate continuous training (MCT) in older adults living in the community. The authors observed significantly greater effectiveness for HIIT (TRX) in parameters of BMI and gait speed (Jiménez-García et al.).

In addition, they observed similar benefits when comparing HIIT vs. MCT in the improvement of the domains of overall health, vitality and physical functioning on the SF-36 questionnaire. It is important to note that the older adults who took part in the HIIT (TRX) group presented basal lower values (grip strength, $\leq 28 \mathrm{~kg}$; gait speed, $<1 \mathrm{~m} /$ sec and quality of life, $\mathrm{PCS}=71.43 \%$ and $\mathrm{MCS}=73.16 \%$ ) compared to the outcomes in this study. Therefore, we presume that our users are functionally healthier.

In this way, it is widely documented that HIIT is an effective strategy to improve quality of life for the older pathological population. Jaureguizar et al. (2016), demonstrated in adults with ischemic cardiopathy that HIIT was superior to MCT in improving the emotional role, mental health and MCS measured by the SF-36 questionnaire (Villelabeitia Jaureguizar et al.). Another study (Mangiamarchi et al.) integrated HIIT + nutritional education for middle-aged people with diabetes mellitus, showed significant improvements in physical function $(+141.7 \%)$, general health $(+125.6 \%)$ and the perception of vitality $(+128.8 \%)$ compared to the control group that only received nutritional education.

The outcomes were different to those observed in this study, with no significant intra-group results in any of the dimensions of quality of life after 12 weeks of HIIT on a cycloergometer. It is worth noting that the healthy subjects in our study initially presented favorable results (prior to the intervention) and that the self-reported SF-36 quality of life questionnaire has a low perception of significant minimum clinical change, which difficult when the initial result obtained is high; however, the changes in the summary components indicate potential benefits after 12 weeks of HIIT on a bicycle. In PCS, the group of older adults recorded the greatest positive changes after HIIT program, which is favorable considering that the current sphere is involved in the greater capacity for daily activities in everyday life and self-care, central components that give the older population well-being. In the young people, the best outcomes were in the MHC.

Our results are consistent with those reported by Engel et al. (2019), worked with young adults for 8 weeks with functional suspension HIIT and also had no significant changes in any of health-related quality-of-life components; however, it is important to emphasize that they used a different self-report instrument (The World Health Organization Quality of Life (WHOQOL-BREF)). In spite of this, the WHO quality-of-life questionnaire (WHOQOLBREF) also indicated changes in standardized mean differences (SMD) more favorable in the dimensions of psychological health, social relations and environment in the subjects involved in this protocol.

Therefore, it is essential to have interventions that can prevent, delay and treat a sedentary lifestyle and sarcopenia during healthy aging through early and effective interventions (Garatachea et al., 2015).

Hence, HIIT is proposed as a health-promoting intervention that contributes to maintaining a healthy population by improving comprehensive assessment parameters closely related to physical and mental well-being, which includes the concept of health.

Within the limitations and due to the study design, we are unable to determine if not performing the intervention (control group) or another training modality is more effective than HIIT. In addition, the use of SF-36 questionnaire in the subjects in this study was limited due to its low sensitivity to perceiving minimum clinical changes in relation to its psychometric properties; however, there is no instrument that exclusively measures quality of life in a healthy population.

\section{CONCLUSION}

In conclusion, HIIT for 12 weeks promotes positive percentage changes in quality of life, with YNG showing better results in PCS and OLD in MCS. Finally, there were moderate correlations between quality of life and anthropometric parameters and lower limb functionality.

ACKNOWLEDGEMENTS. The authors wish to thank Prof. Dr. Erik Díaz for the critical reading of this work, Prof. 
ARTIGAS-ARIAS, M.; OLEA, M. A.; SAN MARTÍN-CALÍSTO, Y.; HUARD, N.; DURÁN-VEJAR, F.; BELTRÁN-FUENTES, F.; MUÑOZ-FERNÁNDEZ, A.; ALEGRÍA-MOLINA, A.; SAPUNAR, J.; SALAZAR, L. A. \& MARZUCA-NASSR, G. N. Anthropometric parameters, lower limb functionality and quality of life after high-intensity interval training in healthy young people versus older adults. Int. J. Morphol., 39(5):1337-1344, 2021.

Dr. Cristian Martinez, Director of the Departamento de Educación Física, Deporte y Recreación at the Universidad de La Frontera for making the equipment and space available for the assessment of maximal aerobic capacity and the highintensity interval training, physiotherapist Marcela Sandoval for her help in performing the DEXA scans, and Dr. Helen M. Lowry for proofreading the article.

GRANTS. This research was carried out using financial support from ANID-FONDECYT - Chile (Grant Number 11180949) and the Dirección de Investigación (DIUFRO) of the Universidad de La Frontera (Grant Numbers DI180068 and DI21-2020).

ARTIGAS-ARIAS, M.; OLEA, M. A.; SAN MARTÍNCALÍSTO, Y.; HUARD, N.; DURÁN-VEJAR, F.; BELTRÁN-FUENTES, F.; MUÑOZ-FERNÁNDEZ, A.; ALEGRÍA-MOLINA, A.; SAPUNAR, J.; SALAZAR, L. A. \& MARZUCA-NASSR, G. N. Parámetros antropométricos, funcionalidad de miembros inferiores y calidad de vida posterior al entrenamiento interválico de alta intensidad en jóvenes versus personas mayors. Int. J. Morphol., 39(5):1337-1344, 2021.

RESUMEN: Determinar los efectos del entrenamiento interválico de alta intensidad (HIIT) sobre la calidad de vida en jóvenes sanos (YNG) y personas mayores (OLD) y su correlación con el estado de salud física (parámetros antropométricos y funcionalidad de miembros inferiores). Ambos grupos, YNG (21 \pm 2 años, IMC $26,37 \pm 2,69 \mathrm{n}=12)$ y OLD $(67 \pm 5$ años, IMC $27,16 \pm 3,04 \mathrm{n}=12$ ) realizaron 12 semanas de HIIT. Antes y después del HIIT, se realizaron evaluaciones antropométricas, pruebas de funcionalidad de miembros inferiores y cuestionario de calidad de vida SF-36. No hubo cambios significativos en las dimensiones del SF-36 (P >0,05). Después del HIIT, hubo cambios porcentuales de mejora en el componente sumario mental (MCS) (YNG, $+8.51 \pm 25.80 \%$ vs. OLD, $+2.30 \pm 9.05 \%)$ y el componente sumario física (PCS) (YNG, $+2,66 \pm 20,54 \%$ vs. OLD $,+2,30 \pm 9,05 \%)$, correspondientes a la calidad de vida. Se observaron correlaciones negativas entre el índice de masa corporal (IMC) con PCS ( $\mathrm{R}=-0,570 ; \mathrm{P}=0,009)$ y con $\mathrm{MCS}(\mathrm{R}=0,649$; $\mathrm{P}=0,002)$ en OLD, así como entre MCS y circunferencia de cintura $(R=-0,557, P \leq 0,001)$ en ambos grupos. Además, se observaron correlaciones entre PCS y la prueba de sentarse y levantarse $(R=-0,424 ; P=0,006)$ en ambos grupos y la velocidad de la marcha $(\mathrm{R}=0,458 ; \mathrm{P}=0,042)$ solo en $\mathrm{YNG}$. HIIT promueve cambios porcentuales positivos en la calidad de vida, con YNG mostrando mejores resultados en PCS y OLD en MCS. La calidad de vida y el estado de salud física se correlacionaron en ambos grupos.

PALABRAS CLAVE: Entrenamiento interválico de alta intensidad; Envejecimiento saludable; Antropometría; Capacidad funcional; Calidad de vida.

\section{REFERENCES}

Adams, S. C.; Delorey, D. S.; Davenport, M. H.; Fairey, A. S.; North, S. \& Courneya, K. S. Effects of high-intensity interval training on fatigue and quality of life in testicular cancer survivors. Br. J. Cancer, 118(10):1313-21, 2018.

Awick, E. A.; Ehlers, D. K.; Aguiñaga, S.; Daugherty, A. M.; Kramer, A. F. \& McAuley, E. Effects of a randomized exercise trial on physical activity, psychological distress and quality of life in older adults. Gen. Hos.p Psychiatry, 49:44-50, 2017.

Bouchard, D. R.; Héroux, M. \& Janssen, I. Association between muscle mass, leg strength, and fat mass with physical function in older adults: Influence of age and sex. J. Aging Health, 23(2):313-28, 2011.

Boutros, G. E. H.; Morais, J. A. \& Karelis, A. D. Current concepts in healthy aging and physical activity: A viewpoint. J. Aging Phys. Act., 27(5):755-61, 2019.

Cancela, J. M.; Mollinedo, I.; Montalvo, S.;\& Vila Suárez, M. E. Effects of a high-intensity progressive-cycle program on quality of life and motor symptomatology in a parkinson's disease population: a pilot randomized controlled trial. Rejuvenation Res., 23(6):508-15, 2020.

Chang, S. P.; Shih, K. Sen, Chi, C. P.; Chang, C. M.; Hwang, K. L. \& Chen, Y. H. Association between exercise participation and quality of sleep and life among university students in Taiwan. Asia Pac. J. Public Health, 28(4):356-67, 2016.

Cruz-Jentoft, A. J.; Bahat, G.; Bauer, J.; Boirie, Y.; Bruyère, O.; Cederholm, T.; Cooper, C.; Land, F.; Rolland, Y.; Sayer, A. A.; et al. Sarcopenia: revised European consensus on definition and diagnosis. Age Ageing, 48(1):16-31, 2019.

Dalmazzo, V.; Ponce, Á.; Delgado-Floody, P.; Carrasco-Alarcón, V. \& Martínez-Salazar, C. Effects of interval exercise in the improvement of glycemic control of obese adults with insulin resistance. Nutr. Hosp., 36(3):578-82, 2019.

Dodds, R. M.; Syddall, H. E.; Cooper, R.; Benzeval, M.; Deary, I. J.; Dennison, E. M.; Der, G.; Gale, C. R.; Inskip, H. M.; Jagger, C.; et al. Grip strength across the life course: normative data from twelve british studies. PLoS One, 9(12):e113637, 2014.

Engel, F. A.; Rappelt, L.; Held, S. \& Donath, L. Can high-intensity functional suspension training over eight weeks improve resting blood pressure and quality of life in young adults? A randomized controlled trial. Int. J. Environ. Res. Public Health, 16(24):5062, 2019.

Garatachea, N.; Pareja-Galeano, H.; Sanchis-Gomar, F.; Santos-Lozano, A.; Fiuza-Luces, C.; Morán, M.; Emanuele, E.; Joyner, M. J. \& Lucia, A. Exercise attenuates the major hallmarks of aging. Rejuvenation Res., 18(1):57-89, 2015.

García-Pinillos, F.; Laredo-Aguilera, J. A.; Muñoz-Jiménez, M. \& LatorreRomán, P. A. Effects of 12-week concurrent high-intensity interval strength and endurance training program on physical performance in healthy older people. J. Strength Cond. Res., 33(5):1445-52, 2019.

Gariballa, S. \& Alessa, A. Association between muscle function, cognitive state, depression symptoms and quality of life of older people: evidence from clinical practice. Aging Clin. Exp. Res., 30(4) 351-7, 2018.

Guralnik, J. M.; Simonsick, E. M.; Ferrucci, L.; Glynn, R. J.; Berkman, L. F.; Blazer, D. G.; Scherr, P. A. \& Wallace, R. B. A short physical performance battery assessing lower extremity function: association with self-reported disability and prediction of mortality and nursing home admission. J. Gerontol., 49(2):85-94, 1994.

Haider, S.; Luger, E.; Kapan, A.; Titze, S.; Lackinger, C.; Schindler, K. E. \& Dorner, T. E. Associations between daily physical activity, handgrip strength, muscle mass, physical performance and quality of life in prefrail and frail community-dwelling older adults. Qual. Life Res., 25(12):3129-38, 2016. 
ARTIGAS-ARIAS, M.; OLEA, M. A.; SAN MARTÍN-CALÍSTO, Y.; HUARD, N.; DURÁN-VEJAR, F.; BELTRÁN-FUENTES, F.; MUÑOZ-FERNÁNDEZ, A.; ALEGRÍA-MOLINA, A.; SAPUNAR, J.; SALAZAR, L. A. \& MARZUCA-NASSR, G. N. Anthropometric parameters, lower limb functionality and quality of life after high-intensity interval training in healthy young people versus older adults. Int. J. Morphol., 39(5):1337-1344, 2021.

Jiménez-García, J. D.; Martínez-Amat, A.; De la Torre-Cruz, M.; FábregaCuadros, R.; Cruz-Díaz, D.; Aibar-Almazán, A.; AchalandabasoOchoa, A \& Hita-Contreras, F. Suspension training HIIT improves gait speed, strength and quality of life in older adults. Int. J. Sports Med., 40(2):116-24, 2019.

Kell, K. P. \& Rula, E. Y. Increasing exercise frequency is associated with health and quality-of-life benefits for older adults. Qual. Life Res., 28(12):3267-72, 2019.

Liu, Y.; Ye, W.; Chen, Q.; Zhang, Y.; Kuo, C. H. \& Korivi, M. Resistance exercise intensity is correlated with attenuation of $\mathrm{HbAlc}$ and insulin in patients with type 2 diabetes: a systematic review and metaanalysis. Int. J. Environ. Res. Public Health, 1 6(1):140, 2019.

MacInnis, M. J. \& Gibala, M. J. Physiological adaptations to interval training and therole of exercise intensity. J. Physiol., 595(9):291530, 2017.

Mangiamarchi, P.; Caniuqueo, A.; Ramírez-Campillo, R.; Cárdenas, P.; Morales, S.; Cano-Montoya, J.; Bresciani, G. \& Álvarez, C. Effects of high-intensity interval training and nutritional education in patients with type 2 diabetes. Rev. Med. Chile, 145(7):845-85, 2017.

Marzuca-Nassr, G. N.; Artigas-Arias, M.; Olea, M. A.; SanMartín-Calísto, Y.; Huard, N.; Durán-Vejar, F.; Beltrán-Fuentes, F.; MuñozFernández, A.; Alegría-Molina, A.; Sapunar, J. \& Salazar, L. A. Highintensity interval training on body composition, functional capacity and biochemical markers in healthy young versus older people. Exp. Gerontol., 141:111096, 2020.

Nelson, M. E.; Rejeski, W. J.; Blair, S. N.; Duncan, P. W.; Judge, J. O.; King, A. C.; Macera, C. A. \& Castaneda-Sceppa, C. Physical activity and public health in older adults: Recommendation from the American College of Sports Medicine and the American Heart Association. Med. Sci. Sports Exerc., 39(8):1435-45, 2007.

Ostman, C.; Jewiss, D. \& Smart, N. A. The effect of exercise training intensity on quality of life in heart failure patients: a systematic review and meta-analysis. Cardiology, 136(2):79-89, 2017.

Rolland-Cachera, M. F.; Cole, T. J.; Sempe, M.; Tichet, J.; Rossignol, C. $\&$ Charraud, A. Body mass index variations: Centiles from birth to 87 years. Eur. J. Clin. Nutr., 45(1):13-21, 1991.

Rowe, J. W. \& Kahn, R. L. Human aging: usual and successful. Science, 237(4811):143-9, 1987.

Snedden, T. R.; Scerpella, J.; Kliethermes, S. A.; Norman, R. S.; Blyholder, L.; Sanfilippo, J.; McGuine T. A. \& Heiderscheit, B. Sport and physical activity level impacts health-related quality of life among collegiate students. Am. J. Health Promot., 33(5):675-82, 2019.

Villelabeitia Jaureguizar, K.; Vicente-Campos, D.; Ruiz Bautista, L.; De La Peña, C. H.; Arriaza Gómez, M. J.; Calero Rueda, M. J. \& Fernández Mahillo, I. Effect of high-intensity interval versus continuous exercise training on functional capacity and quality of life in patients with coronary artery disease: a randomized clinical trial. J. Cardiopulm. Rehabil. Prev., 36(2):96-105, 2016.

Wang, L.; Crawford, J. D.; Reppermund, S.; Trollor, J.; Campbell, L.; Baune, B. T.; Sachde, P.; Brodaty, H.; Samaras, K. \& Smith, E. Body mass index and waist circumference predict health-related quality of life, but not satisfaction with life, in the elderly. Qual. Life Res., 27(10):2653-65, 2018

Ware, J. E. \& Sherbourne, C. D. The MOS 36-ltem Short-Form Health Survey (SF-36). Med. Care, 30(6):473-83, 1992.
Corresponding author:

Gabriel Nasri Marzuca-Nassr

Faculty of Medicine

Universidad de La Frontera

Claro solar 115

Temuco

CHILE

E-mail: gabriel.marzuca@ufrontera.cl

Received: 07-06-2021

Accepted: 13-07-2021 